Бунчук В.Л.

\title{
ФЕДЕРАЛИЗМ И ИНСТИТУТЫ ГРАЖДАНСКОГО ОБЩЕСТВА В СОВРЕМЕННОЙ РОССИИ
}

\begin{abstract}
Аннотация: Гражданское общество является одной из самых неоднозначных категорий в политической науке. Содержание этой категории во многом определяется сочиально-политическим контекстом конкретного исторического периода; до сих пор в отномении гражданского общества в академической среде не сложилось общего мнения. Однако понятие гражданского общества крайне часто используется ведущими политическими деятелями многих государств и международных организаций. Поиск общего стержня в многообразии интерпретаций понятия гражданского общества продолжает оставаться крайне актуальной задачей.
\end{abstract}

Review: Civil society is one of the most controversial categories in political science. The content of this category is mostly defined by the socio-political environment of a particular period in history. Educational community still hasn't formed a general opinion on civil society. However, the term 'civil society' is often used by the leading political figures in many countries and international organizations. Creation of a general definition of civil society is still a very important task to be solved.

Ключевые слова: Политология, политика, общество, гражданское общество, институт, федерализм, государство, власть, конфликт, политическая система

Keywords: political studies, policy, society, civil society, institution, federalism, state institution, government, conflict, political system.

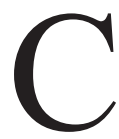

егодня только начинает активно прорабатываться институциональный подход применительно к пространству гражданского общества. В частности, такие процессы как формирование и развитие институтов гражданского общества с позиций именно институционального подхода практически не исследованы в современной политической науке. В отсутствии четкого понимания особенностей генезиса и эволюции институтов гражданского общества невозможно обосновать выбор и саму эффективность ни одного средства воздействия на эти значимые процессы.

Принимая во внимание обозначенные выше проблемы, рассмотрим основные подходы к пониманию процессов формирования и развития институтов гражданского общества, а также дадим характеристику актуальному состоянию институтов гражданского общества в современной России. Для определения специфики институтов гражданского общества необходимо рассмотреть следующие теоретико-методологические вопросы: 1) проанализировать разнообразные интерпретации сущности института; 2) опираясь на результаты анализа разнообразных интерпретаций гражданского общества в современной политологической литературе, обозначить свою позицию в отношении определения гражданского общества и его институтов; 3) определиться с методологией исследования процессов формирования и развития институтов гражданского общества. В рамках последней задачи выделим основные модели формирования институтов гражданского общества, а также определимся с набором критериев уровня развития институтов гражданского общества; затем охарактеризуем институциональное разнообразие и особенности российского гражданского общества и выделим основные уровни в его структуре; выявим факторы, оказывающие негативное влияние на формирование и развитие 
институтов гражданского общества в современной России.

Безусловно, развитое гражданское общество и правовое государство - это идеальный общественно-политический проект. Это социальная модель, к которой человечество шло долгий период, испытав на себе самые разные конструкции организации своего бытия. Но именно построение такого общества является приоритетом в современной России. Примерами могут служить особое отношение к данной задаче, содержащееся во всех Посланиях Президента России Федеральному Собранию, а также включение задачи по развитию институтов гражданского общества в национальные планы социально-экономического развития с обозначением соответствующих объемов бюджетного финансирования.

В частности, Программой социально-экономического развития Российской Федерации на среднесрочную перспективу (2006-2008 годы) были предусмотрены такие задачи как: модернизация законодательства, регулирующего деятельность НКО (некоммерческих организаций); обеспечение равных условий доступа негосударственных и государственных некоммерческих организаций на рынки социальных услуг; обеспечение прозрачности деятельности НКО, органов государственной власти и органов местного самоуправления; развитие механизмов независимой общественной экспертизы и государственно-общественных консультаций на ранних стадиях подготовки и принятия решений; развитие механизмов общественного мониторинга; создание механизмов, способствующих усилению социальной ответственности бизнеса; развитие системы гражданского образования. Данные задачи обозначены и в проекте Концепции долгосрочного социальноэкономического развития Российской Федерации, являющейся фундаментом так называемой «Стратегии 2020»'. Таким образом, российская власть декларирует государственные задачи по созданию необходимых условий для формирования и развития институтов гражданского общества.

\footnotetext{
${ }^{1}$ См.: Выступление Президента РФ Владимира Путина на расширенном заседании Государственного совета «О стратегии развития России до 2020 года». 8 февраля 2008 года, Москва, Кремль // http://www.edinros.ru/news.html?id=127560. -2008 .
}

Особо отметим, что исторически в России сложилась такая система построения гражданского общества, при которой роль «главного архитектора» в силу различных причин исполняет государственная власть, а тот или иной вид государственной политики связывается преимущественно с системой органов государственной власти. Альтернативные инициативы в большинстве случаев осуществляются с оглядкой на власть. В частности, анализируя работу некоторых институтов гражданского контроля в современной России, А.М. Шустров, будучи начальником отдела департамента имущества города Москвы, приходит к примечательному выводу о том, что процесс формирования институтов гражданского контроля над деятельностью власти в основном инициирует сама же власть ${ }^{2}$.

При этом рассуждения о российской специфике становления гражданского общества исключительно в категориях «хорошо/плохо» представляются нам в научном плане мало продуктивными. В силу этого весьма актуальной задачей становится научная рефлексия процессов формирования и развития институтов гражданского общества в современной России с учетом мировых тенденций, специфики российской истории и культуры, а также особенностей государственного развития России в самых различных сферах.

В самой структуре гражданского общества современной России можно выделить институты и институции муниципальной (органы и учреждения местного самоуправления), коммерческой (бизнес-структуры) и некоммерческой направленности («третий сектор», сектор НКО). В целом данная структура и представляет собой институционально-организационный дизайн гражданского общества современной России.

Местное самоуправление (МСУ) - важнейший институт гражданского общества, охватывающий огромное множество различных структур и организаций: от органов местного самоуправления и муниципальных учреждений (детских садов, школ, клубов и т.д.) до местных сообществ граждан.

В России на конституционном уровне за органами местного самоуправления закреплено пра-

\footnotetext{
${ }^{2}$ См.: Шустров, А.М. Функционирование некоторых институтов гражданского контроля в регионах России // Власть. 2009. №8. С. 43-45.
} 


\section{Политика и общество 11 (107) • 2013}

во самостоятельно решать вопросы, находящиеся в их ведении. Однако, как отмечается в Докладе Общественной палаты РФ от 2007 года, «практически повсеместно наблюдается тенденция подавления со стороны региональной и районной власти способности МСУ самостоятельно решать вопросы местного значения» ${ }^{3}$. Исключением из правил являются некоторые крупные и средние города, в том числе региональные центры.

Безусловно, такая зависимость органов местного самоуправления в современной России от государственной власти превращает этот важнейший институт демократии в придаток огромной бюрократической машины под названием «система органов государственной и муниципальной власти». В таких условиях институт местного самоуправления перестаёт быть институтом гражданского общества и становится институтом организации власти на местном уровне.

Таким образом, теперь уже в структуре самого института местного самоуправления в современной России чётко прослеживаются два полюса: с одной стороны, это органы муниципальной власти, которые в большинстве случаев копируют стиль поведения власти региональной (а она по Конституции России является властью государственной), а с другой стороны - это весьма «вялые» и малочисленные местные сообщества граждан, целью деятельности которых зачастую является борьба с органами муниципальной власти. Так как в тотальном большинстве случаев победу в этой борьбе одерживает муниципальная власть, ориентированная на власть региональную, а местные сообщества очень пассивны и малочисленны, то говорить о российском местном самоуправлении как об эффективном институте гражданского общества, т.е. таком институте, который реально может влиять на государственную власть и отстаивать интересы конкретных граждан, просто не приходится.

Однако проблематика российского местного самоуправления гораздо шире и не сводится к конфликту интересов различных уровней государственной и муниципальной властей, в силу тех или иных обстоятельств вовлечённых в про-

3 Доклад Общественной палаты Российской Федерации о состоянии гражданского общества в Российской Федерации - 2007 год. М., 2008. 71 с. С.63-67. цесс управления местной территорией. В центре местного самоуправления находится не управленческий аппарат, а граждане, проживающие на конкретной территории. И основной задачей демократического развития местного самоуправления должно являться вовлечение этих самых граждан в процесс управления территорией проживания, мобилизация населения в целях наращивания полезного социального капитала на определенной территории.

Ещё от советской системы россиянам досталась такая модель местного самоуправления («местные советы народных депутатов»), которая не предполагала свободной самоорганизации жителей. В итоге за годы советской власти не сформировалась практика гражданских инициатив на местном уровне. Добровольно-принудительный принцип участия жителей в различных проектах местных советов, по сути, привёл к дискредитации местного самоуправления как эффективного социального института в глазах граждан. Однако в советский период можно было наблюдать некую компенсацию: в частности, под страхом общественного (партийного) осуждения советские граждане следили за своим общим двором, активно посещали субботники и иные форматы общественно-хозяйственных работ.

Воссоздать «машину давления» на граждан в современных условиях просто невозможно и крайне опасно, поэтому остаётся только один путь развития местного самоуправления: активизация гражданского участия в управлении территорией проживания. Здесь мы сталкиваемся с тем, что у большинства наших граждан практически не было за всю историю новой России опыта самостоятельного участия в управлении местной территорией.

Органы местного самоуправления в той форме, в которой они существуют в современной России, явно пока не справляются со своими основными задачами. К тому же опыт в этой сфеpe накоплен пока очень скудный. Может быть, пройдет некоторое время, и граждане смогут реально реализовывать те функции, которыми они наделены действующим законодательством. Однако что делают сейчас российские граждане в данной ситуации? Вместо создания сильных местных сообществ они либо проявляют недюжинное терпение, либо пытаются решить проблему через влиятельных знакомых во власти, либо 
обращаются к мэру, депутату, губернатору, Президенту, в последнее время также в суд или прокуратуру. Представляется, что делают они это в силу давней российской традиции, берущей своё начало в вере в «доброго царя». То есть, налицо замещение института местного самоуправления институтом личных связей и институтом обращения граждан в высшие инстанции - даже по самым мелким бытовым проблемам.

И лишь небольшая часть граждан, явно уставших от недееспособности своих муниципалитетов и местных управляющих компаний, крайне медленно и неуверенно, начинает пользоваться теми форматами самоорганизации, которые гарантирует закон. Граждане начинают объединяться в местные сообщества, наиболее популярными формами институциализации которых являются гражданские органы самоуправления в виде ТОС (территориальное общественное самоуправление) и ТСЖ (товарищество собственников жилья). Среди прочих проблем, которые пытаются решить эти объединения граждан, наиболее массовыми проблемами являются: угроза сноса домов, точечная застройка, ремонт жилья, обустройство детских площадок, гаражная проблема, конфликты с застройщиком. В ряде случаев наиболее активным объединениям граждан удается отстоять свои права, организуя массовые собрания и митинги, привлекая на свою сторону влиятельных и авторитетных журналистов, общественников, деятелей культуры, спорта, науки, придавая тем самым своей локальной проблеме публичный характер.

Особо хотелось бы отметить, что борьба за свои права - не единственная форма активности российских граждан. Самоорганизация граждан на уровне местного самоуправления в современной России начинает покрывать и другие сферы гражданских инициатив: взаимопомощь, благотворительность, добровольчество, малый бизнес в самых различных его форматах, включая и такой формат как «протребление» ${ }^{4}$. Однако самоорганизация в России не является явлением массовым и, тем более, - явлением само собой разумеющимся и своего рода привычным для граждан.

${ }^{4}$ См.: Тоффлер, Э. Революционное богатство: Пер. с англ. / Э.Тоффлер, Х.Тоффлер. - М. : АСТ, 2008. - 569 с.
Следующим важным вопросом является определение принадлежности частного бизнеса частной собственности. Существует как минимум три точки зрения: одни относят частный бизнес к сфере гражданского общества, другие - к личной жизни граждан, третьи - выделяют бизнес в отдельную сферу жизнедеятельности людей. По данному вопросу мы будем придерживаться той точки зрения, что частный бизнес - это один из сегментов гражданского общества (включающий в себя ряд специфических институтов), и он не может быть лишь частью личной жизни граждан, так как предполагает социальные интеракции - совокупность взаимодействий одного человека с другим с целью извлечения коммерческой прибыли.

Именно с этих позиций О.И. Цыбулевская определяет гражданское общество как систему экономических, нравственных, религиозных и других отношений индивидов, свободно и добровольно объединившихся в гражданские ассоциации, союзы для удовлетворения своих, материальных, духовных интересов и потребностей 5 . В свою очередь Е. Малкин и Е. Сучков к формам и институтам гражданского общества относят: свободное предпринимательство, местное самоуправление, политические партии, профсоюзы и общественные организации, некоммерческие организации (религиозные, научные, спортивные, благотворительные, по интересам, по убеждениям, по целям), свободные, негосударственные СМИ, граждан ${ }^{6}$.

Влияние частного (негосударственного) бизнеса на власть в современной России, а также роль негосударственных коммерческих организаций в структуре гражданского общества исследованы в отечественной политологии крайне неполно и поверхностно. К сожалению, фокус внимания исследователей в данном случае неоправданно смещён в сторону изучения лоббистской деятельности крупных финансово-промышленных групп и транснациональных корпораций, благотворительности и феномена спонсорства коммерческих организаций в гражданских прак-

\footnotetext{
${ }^{5}$ Становление гражданского общества в России: Правовой аспект / Под ред. О.И.Цыбулевской. Саратов, 2002. С.14.

${ }^{6}$ Малкин, Е., Сучков, Е. Политические технологии. М.: «Русская панорама», 2006. - 680 с. С.10-11.
} 


\section{Политика и общество 11 (107) • 2013}

тиках. Представляется, что в эпоху сетевых и партнерских структур частный бизнес следует рассматривать в качестве полноправного участника социальных практик, обусловленных задачами развития гражданского общества. Безусловно, институты гражданского общества нуждаются в ресурсах; без финансовых вливаний со стороны бизнеса институтам гражданского общества в современной России приходится очень туго; им просто не выжить. Связано это с тем, что в нашей стране так и не сформировался пресловутый «средний класс» с активной гражданской позицией. Именно этот «средний класс» финансирует большинство гражданских инициатив на Западе. Поэтому совершенно логично и закономерно обращение общественных институтов за финансовой помощью к частному бизнесу. Однако не менее логичным выглядит и модель, при которой институты гражданского общества финансируются за счет государственных (народных) средств - из федерального бюджета или бюджетов субъектов Российской Федерации.

«Свободное» от системы местного самоуправления и частного бизнеса гражданское общество называют «третьим сектором» или сектором НКО (сектором некоммерческих организаций), т.е. негосударственным (неправительственным) некоммерческим гражданским обществом. Наиболее распространенной формой негосударственных некоммерческих организаций являются общественные объединения, которые, в свою очередь, делятся на общественные организации, общественные движения, общественные фонды, общественные учреждения, органы общественной самодеятельности и политические партии. К иным негосударственным некоммерческим организациям относятся религиозные организации, социальные и благотворительные фонды, некоммерческие партнерства, негосударственные и немуниципальные учреждения, автономные некоммерческие организации, объединения некоммерческих организаций (ассоциации и союзы). Число негосударственных некоммерческих организаций в России на 1 января 2011 года составило около 342 тыс. организаций ${ }^{7}$.

\footnotetext{
7 Доклад Общественной палаты Российской Федерации о состоянии гражданского общества в Российской Федерации - 2011 год. М., 2012. 148 с. С.16.
}

«Третий сектор» представляет собой организационную основу институтов гражданского общества. Действительно, без политических партий, свободной прессы, общественных организаций (правозащитных, экологических и др.), религиозных организаций, профессиональных союзов, независимых исследовательских и экспертных центров гражданское общество просто немыслимо и беспомощно. Именно эти ключевые институции, ориентируясь на идеальный образ гражданского общества, формируют его институты и создают пространство социальных практик.

Анализируя в 2006 году состояние гражданского общества в современной России, эксперты Общественной палаты России пришли к выводу, что структуры гражданского общества в нашей стране пока ещё не образуют плотную общественную среду, формированию которой необходимо содействовать через создание благоприятных информационных, правовых, экономических и других предпосылок и условий для развития общественных структур. Также экспертами отмечается низкая общественная активность граждан в масштабах всей страны (не только в Москве и других крупнейших городах, но и в регионах, на периферии), недостаточная наглядность позитивной роли общественных структур, слабая информированность о них и серьезный дефицит доверия граждан друг к другу, к структурам власти и институтам гражданского общества. Аналогичные проблемы обозначены и в последующих ежегодных докладах о состоянии гражданского общества в России, а также в исследованиях российских и зарубежных экспертов ${ }^{8}$.

Актуальным в отечественном политологическом дискурсе остается вопрос о том, в какой

\footnotetext{
${ }^{8}$ См.: Гражданское общество в модернизирующейся России [Электронный ресурс]: аналитический доклад Центра исследований гражданского общества и некоммерческого сектора НИУ ВШЭ по итогам реализации проекта «Индекс гражданского общества - CIVICUS» / Л.И.Якобсон, И.В.Мерсиянова, О.Н. Кононыхина и др. - М. : НИУ ВШЭ, 2011; Волков, Д. Перспективы гражданского общества в России. Доклад Аналитического Центра Юрия Левады (Левада-Центр). М., 2011. - 50 с.; Ланг, С. Гражданское общество и гражданская активность в России / С.Ланг, А.Хартель, М.Бюрш // Аналитический доклад по результатам исследования. Берлин : Фонд имени Фридриха Эберта, 2010. - 25 с. и др.
} 
мере институты гражданского общества современной России выполняют ключевую функцию гражданского общества, понимаемого в широком смысле, как пространства самоорганизации граждан между государством и частной жизнью, производящего социальный капитал, повышающий доверие граждан друг к другу, а также к политическим и общественным институтам, - функцию защиты прав одного социального актора от «тоталитарных» устремлений другого.

Необходимо отметить, что основным субъектом тоталитарных устремлений в России продолжает оставаться бюрократия, понятая как «система органов государственной и муниципальной власти». Особенностью России в данной ситуации является то, что в отсутствие более эффективного борца с бюрократией она борется сама с собой. Пассивное, разрозненное и, лучше сказать, не уверенное в себе российское гражданское общество вынуждает власть самой искать внутри себя возможности для борьбы со своими недугами. По большому счету, российским гражданам активный «третий сектор» не нужен, так как в противном случае им придется принимать участие в работе этого сектора, что опять-таки слабо коррелируется с их менталитетом и тускло выраженной гражданской позицией. Наверное, проще иметь сильную власть и несколько «крикливых» общественных организаций для «выпускания пара». При этом нельзя не отметить, рост уличной протестной активности, но и она не носит системного характера.

Однако такова наша российская действительность, такова модель нашего гражданского общества. И не стоит, на наш взгляд, резко и необдуманно трансформировать эту действительность, насаждая новые общественные институты по западному образцу. Они рискуют превратиться в социальные декорации, они рискуют стать «институтами-симулякрами» ${ }^{9}$, что собственно и произошло со многими социальными институтами в современной России. Но в то же время, не

\footnotetext{
9 М.С.Григорьев в одной из своих последних работ для подобных структур гражданского общества вводит специальное название - «fake-структуры» (от англ. fake - поддельный, фальшивый). См.: Григорьев, М.C. Fake-структуры: призраки российской политики. - М.: Издательство «Европа», 2007. - 216 с.
}

меньшим риском будет игнорирование опыта зарубежных институтов гражданского общества, которые являются эффективными, в том числе в плане приращения социальных, политических и экономических благ.

Помимо уже обозначенных особенностей российского гражданского общества и его институтов, выделим ещё несколько важных аспектов. В частности, в России наблюдается крайне высокая степень персонифицированности институтов гражданского общества, что, впрочем, характерно для всей российской институциональной системы. Школа прочно ассоциируется с директором, политическая партия - с партийным лидером, газета - с редактором и т.д. В этом плане российские институты гражданского общества зависимы от персоналий, что само по себе противоречит определению института, так как последний - образование устойчивое относительно конкретных личностей.

Зачастую институты гражданского общества создаются в России под конкретного человека, и пока тот в состоянии управлять ими - они функционируют. Данный фактор необходимо учитывать в процессах формирования и развития российского гражданского общества. Это не изъян, это особенность. В частности, в докладе Института общественного проектирования «Оценка состояния и перспектив политической системы РФ в 2008 году - начале 2009» прямо указывается на особую роль политических лидеров современной России в условиях «слабости институтов, которые не оживляются «изнутри» ${ }^{10}$.

Высокую степень персонифицированности институтов гражданского общества в современной России дополняет высокая степень влияния на эти институты так называемых «неформальных отношений». Сочетание своеобразной политической культуры россиян с переходным состоянием от советской авторитарной модели управления к демократической предопределили особый стиль влияния политических институтов

\footnotetext{
10 Основные тезисы ежегодного доклада Института общественного проектирования «Оценка состояния и перспектив политической системы Российской Федерации в 2008 году - начале 2009» // Информационноаналитическое обозрение ЦСКП в ЦФО «В центре притяжения». 2009. №2(8). С.20.
} 


\section{Политика и общество 11 (107) • 2013}

на институты гражданского общества в современной России. Наиболее полно и детально этот вопрос разработан А.Д. Хлопиным, который приходит к следующим выводам: власть по отношению гражданам действует непоследовательно и произвольно, применяя то авторитарный, то либеральный стиль управления, что в сочетании с несоблюдением прав индивидов приводит к ответному стремлению граждан избежать исполнения своих обязанностей и соблюдения правовых норм. В результате граждане погружаются в неформальные отношения, в которых находят компенсацию отсутствия правовых гарантий ${ }^{11}$.

Выражаясь образно, можно сказать, что в России значительная часть гражданского общества «утонула» в частных контактах и родственных связях. Ю. Хабермас назвал это явление «гражданской приватностью», являющейся одной из форм пассивной гражданской самоорганизации ${ }^{12}$. Возможно, не находя соответствующих условий в общественной сфере, российские граждане пытаются компенсировать нехватку публичности в сфере частной, расширяя круг неформальных отношений. Представляется, что это явление связано не только с ментальными особенностями, но и во многом определяется низким уровнем благосостояния российских граждан. Так как публичная гражданская активность требует создания и поддержания специальных институтов и структур, зачастую весьма дорогостоящих, российские граждане стараются использовать в публичных целях свои непубличные частные ресурсы.

Ещё одной важной особенностью российского гражданского общества, однозначно определяемой нами в качестве негативной, является его внутренняя раздробленность и противоречивость. Попытки объединения множества близких по духу и целям структур гражданского общества в современной России, как правило, оказываются несостоятельными. Яркой тому иллюстрацией можно считать неудавшиеся проекты по объединению так называемой демократической оппозиции в преддверии декабрьских выборов 2007 года в Государствен-

${ }^{11}$ См.: Институциональная политология: Современный институционализм и политическая трансформация России» / Под ред. С.В. Патрушева. - М.: ИСП РАН, 2006.

${ }^{12}$ См.: Habermas, J. Legitimation Crisis. Boston. 1975. P. 68-75. ную Думу России. Этот феномен также можно объяснить неспособностью именно институциональных лидеров найти консенсус между собой. А сами граждане всё ещё остаются в роли пассивных последователей, не способных оказывать активное влияние на своих лидеров, что тоже говорит о недостаточной зрелости гражданского общества.

Следует отметить, что курс на формирование и развитие институтов гражданского общества в современной России сталкивается с целым рядом проблем. К числу наиболее значимых проблемы мы относим следующие: низкая публичная активность граждан, неразвитая практика гражданской самоорганизации, высокая степень персонифицированности институтов и структур, крайне низкое доверие граждан друг к другу и к институтам власти на фоне устойчивых патерналистских настроений, значительная роль неформальных отношений в публичной сфере, искусственный (декоративный) и симулятивный характер многих структур и проектов, внутренняя раздробленность и противоречивость. Помимо этого, ряд институтов и структур гражданского общества в современной России зачастую искусственно оторваны от государства, что лишает их возможности совместно с органами государственной власти участвовать в решении социально значимых проблем.

Завершая исследование формирования и развития институтов гражданского общества и особенностей этих процессов применительно к российской практике, подведем итоги наших рассуждений. Безусловно, основной проблемой, с которой пришлось столкнуться в рамках исследования теоретико-методологических основ формирования и развития институтов гражданского общества, является крайне слабая проработанность в отечественной политической науке институционального подхода к множественным явлениям гражданского общества. Если оставить это важное замечание за скобками, то в отношении специфики формирования и развития институтов гражданского общества в современной России стоит особо выделить то, что эти процессы протекают не так быстро и зачастую не по тем сценариям, которые обсуждались в эпоху перемен - в рамках острых дискуссий о том, по какому именно пути нужно идти России после болезненной трансформации советской системы. 
Однако гражданское общество в современной России все-таки сложилось: государственная власть не поглощает собой все общество, у граждан есть реальная возможность выдвигать инициативы и облекать их в самые разные организационно-институциональные формы. При этом не следует забывать, что российское гражданское общество, как и гражданские общества других демократических или демократизирующихся государств, своеобразно и, если верить международным рейтингам, не самое слабое в мире ${ }^{13}$.

Многообразные негативные факторы (слабость институтов гражданского участия, их персонифицированность, внутренняя раздробленность и др.) не могут перечеркнуть сам курс на построение в России гражданского общества со всем многообразием его институтов. Выступая на II Bceроссийском гражданском форуме, организатором которого выступила Общественная палата РФ, Д.А. Медведев дал следующую оценку нынешнему гражданскому обществу России: «Наше гражданское общество рождалось в противоречивых событиях последних двух десятилетий. Но то, что оно сегодня является элементом политической жизни - это неоспоримый факт. Больше того, структурированное гражданское общество, сейчас проходит процесс его оформления, уже имеется, и в дальнейшем оно должно стать итогом нашего стабильного цивилизованного развития ${ }^{14}$.

Представляется, что для полноценного достижения этой важнейшей стратегической задачи необходимо особое внимание обращать на те глобальные процессы, которые в настоящее время протекают в мире, и, что самое главное, - пытаться вырабатывать такие реакции на эти процессы, которые бы позволяли прогрессивно развиваться нашим собственным отечественным институтам гражданского общества. Особо отметим, что на современном этапе мирового развития к задаче укрепления гражданского общества в современной России добавляется задача адаптации институтов гражданского общества к условиям глобального информационного социума.

\footnotetext{
${ }^{13}$ См.: Проблемы применения международных рейтингов: общество, государство, экономика / С.А. Николаенко, Е.В. Белянова, О.В. Смородинов. М. : Фонд «ЭРГО», 2009. - 164 с.

${ }^{14}$ Потенциал гражданского общества России // http://www.oprf.ru/newsblock/news/1567/chamber_news. - 2008.
}

\section{Библиография:}

1. Выступление Президента РФ Владимира Путина на расширенном заседании Государственного совета «О стратегии развития России до 2020 года». 8 февраля 2008 года, Москва, Кремль // http:// www.edinros.ru/news.html?id=127560. -2008.

2. Шустров, А.М. Функционирование некоторых институтов гражданского контроля в регионах России // Власть. 2009. №8. С. 43-45.

3. Доклад Общественной палаты Российской Федерации о состоянии гражданского общества в Российской Федерации - 2007 год. М., 2008. 71 с. С.63-67.

4. Тоффлер, Э. Революционное богатство: Пер. с англ. / Э.Тоффлер, Х.Тоффлер. - М. : АСТ, 2008. - 569 с.

5. Становление гражданского общества в России: Правовой аспект / Под ред. О.И.Цыбулевской. Саратов, 2002. С.14.

6. Малкин, Е., Сучков, Е. Политические технологии. М. : «Русская панорама», 2006. - 680 с. С.10-11.

7. Доклад Общественной палаты Российской Федерации о состоянии гражданского общества в Российской Федерации - 2011 год. М., 2012. 148 с. С.16.

8. Гражданское общество в модернизирующейся России [Электронный ресурс]: аналитический доклад Центра исследований гражданского общества и некоммерческого сектора НИУ ВШЭ по итогам реализации проекта «Индекс гражданского общества - CIVICUS» / Л.И.Якобсон, И.В.Мерсиянова, О.Н. Кононыхина и др. - М. : НИУ ВШЭ, 2011;

9. Волков, Д. Перспективы гражданского общества в России. Доклад Аналитического Центра Юрия Левады (Левада-Центр). М., 2011. - 50 с.;

10. Ланг, С. Гражданское общество и гражданская активность в России / С.Ланг, А.Хартель, М.Бюрш // Аналитический доклад по результатам исследования. Берлин : Фонд имени Фридриха Эберта, 2010.

11. Григорьев, M.C. Fake-структуры: призраки российской политики. - М. : Издательство «Европа», 2007. - 216 c.

12. Основные тезисы ежегодного доклада Института общественного проектирования «Оценка состояния и перспектив политической системы Российской Федерации в 2008 году - начале 2009» // Информационно-аналитическое обозрение ЦСКП в ЦФО «В центре притяжения». 2009. №2(8). С.20.

13. Институциональная политология: Современный институционализм и политическая трансфор- 


\section{Политика и общество 11 (107) • 2013}

мация России» / Под ред. С.В. Патрушева. - М.: ИСП РАН, 2006.

14. Habermas, J. Legitimation Crisis. Boston. 1975. P. 68-75.

15. Проблемы применения международных рейтингов: общество, государство, экономика / С.А.Николаенко, Е.В.Белянова, О.В.Смородинов. М. : Фонд «ЭРГО», 2009. - 164 с.

16. Потенциал гражданского общества России // http://www.oprf.ru/newsblock/news/1567/chamber_ news. -2008 .

\section{References (transliteration):}

1. Shustrov, A.M. Funktsionirovanie nekotorykh institutov grazhdanskogo kontrolya v regionakh Rossii // Vlast’. 2009. №8. S. 43-45.
2. Toffler, E. Revolyutsionnoe bogatstvo: Per. s angl. / E.Toffler, Kh.Toffler. - M. : ACT, 2008. - 569 s.

3. Malkin, E., Suchkov, E. Politicheskie tekhnologii. M. : «Russkaya panorama», 2006. - 680 s. S.10-11.

4. Volkov, D. Perspektivy grazhdanskogo obshchestva v Rossii. Doklad Analiticheskogo Tsentra Yuriya Levady (Levada-Tsentr). M., 2011. - 50 s.;

5. Lang, S. Grazhdanskoe obshchestvo i grazhdanskaya aktivnost' v Rossii / S.Lang, A.Khartel', M.Byursh // Analiticheskii doklad po rezul'tatam issledovaniya. Berlin : Fond imeni Fridrikha Eberta, 2010.

6. Grigor'ev, M.S. Fake-struktury: prizraki rossiiskoi politiki. - M. : Izdatel'stvo «Evropa», 2007. - $216 \mathrm{~s}$.

7. Institutsional'naya politologiya: Sovremennyi institutsionalizm i politicheskaya transformatsiya Rossii» / Pod red. S.V. Patrusheva. - M.: ISP RAN, 2006.

8. Habermas, J. Legitimation Crisis. Boston. 1975. P. 68-75. 